\title{
Probiotics in allergic rhinitis
}

\author{
Uso de probióticos na rinite alérgica
}

\section{Janaina Cândida Rodrigues Nogueira ${ }^{1}$, Maria da Conceição Rodrigues Gonçalves ${ }^{2}$}

\section{Keywords:}

bifidobacterium, lactobacillus, rhinitis, probiotics.

\section{Palavras-chave:}

bifidobacterium, lactobacillus, probióticos, rinite.

\begin{abstract}
$\mathrm{P}$

1 robiotics are live microorganisms used as supplementary food, usually lactic acid bacteria that can change either the composition and/or the metabolic activities of the gut microbiota modulating the immune system in a way that benefits the person's health. Aim: To review the use of Probiotics (Lactobacillus and Bifidobacterium) in allergic rhinitis patients. Materials and Methods: Pubmed original articles were used as data source. Results: Results indicate that probiotics, Lactobacillus and Bifidobacterium appear to prevent allergy recurrences, alleviate the severity of symptoms and improve the quality of life of patients with allergic rhinitis. This happens because of the immune system modulation through the induction of cytokine production which cause a dominant TH1 response in allergic patients by modulating the TH1/TH2 balance effect. Conclusion: The use of probiotic bacteria could be an effective and safe way to prevent and/or treat allergic rhinitis, but its underlying mechanisms remain unclear. Therefore, clinical studies using probiotics and dietary intervention should be the focus of future research to enable a more widespread use.
\end{abstract}

\section{Resumo}

$\mathrm{P}$ 1 robióticos são microrganismos viáveis, usados como suplemento alimentar, normalmente bactérias ácidas lácticas, que podem modificar a composição e/ou a atividade metabólica da microbiota intestinal, modulando o sistema imune de forma que beneficie a saúde do indivíduo. Objetivo: Fazer uma revisão sobre o uso de Probióticos (Lactobacillus e Bifidobacterium) na rinite alérgica. Material e Método: Foram pesquisados artigos originais no Pubmed. Resultados: Os resultados encontrados indicam que os probióticos, Lactobacillus e Bifidobacterium parecem prevenir as recorrências alérgicas, aliviar a severidade dos sintomas e promover melhora da qualidade de vida dos pacientes com rinite alérgica. Estes efeitos ocorrem devido à modulação do sistema imunológico através da indução da produção de citocinas que promovem uma resposta TH1 dominante em alérgicos, através do efeito da modulação no balanço TH1/TH2. Conclusão: O uso de bactérias probióticas pode ser uma forma efetiva e segura de prevenção e/ou tratamento de rinite alérgica, mas seu mecanismo exato de ação permanece desconhecido. No entanto, estudos clínicos usando probióticos e intervenção dietética deverão ser o foco de futuras investigações, para permitir um uso mais amplo. 


\section{INTRODUÇÃO}

A rinite alérgica é uma doença inflamatória nasal decorrente do contato de substâncias estranhas, denominadas antígenos, com um indivíduo sensibilizado. É bastante frequente no mundo atual, acometendo indivíduos de ambos os sexos e todas as idades. Pode apresentar desde sintomas leves a sintomas que diminuem a qualidade de vida e a produtividade do indivíduo, temporária ou permanentemente, se não houver tratamento adequado ${ }^{1}$.

Atualmente, tanto em países desenvolvidos, quanto nos ditos em desenvolvimento, observa-se um perfil de doenças diferente de décadas passadas, com predomínio de doenças alérgicas, autoimunes e inflamatórias crônicas, em detrimento das doenças infecciosas. Parte deste fenômeno deve-se à "Hipótese da Higiene," segundo a qual as mudanças no estilo de vida das pessoas, como na alimentação, com consumo de produtos industrializados, ricos em conservantes e outros produtos químicos, bem como a redução do contato de crianças com microrganismos, devido às melhores condições de higiene e vacinação, propiciariam mudanças nas características imunológicas do indivíduo ${ }^{2}$.

Quando uma substância estranha entra em contato com o organismo, é fagocitada e processada pelas células apresentadoras de antígeno. Estas células expõem este antígeno em sua membrana, a partir do complexo de histocompatibilidade (HLA) - classe II, que ao interagir com receptor na membrana do linfócito $\mathrm{T}$ CD4+ promove a proliferação de um clone específico de células $\mathrm{T}$ helper tipo 1 ou tipo 2, que de acordo com as citocinas secretadas, irão propiciar um tipo de reação imunológica ${ }^{3}$.

A linhagem de células helper 1 secreta TNF Beta (fator de necrose tumoral) e interferon $\mathrm{C}$ que ativam células envolvidas na imunidade celular, ou seja, na defesa contra organismos intracelulares como vírus e outros microrganismos que infectam o interior da célula, células defeituosas e cancerosas. A linhagem T helper 2 secreta IL-4, IL-5, IL10, IL13 que estimulam células que participam da reação alérgica, como linfócitos B secretores de IgE, mastócitos e eosinófilos ${ }^{4}$.

O que, segundo alguns autores, explicaria a "Hipótese da Higiene" seria um maior predomínio da linhagem Th2 em relação a Th1, sendo um dos fatores envolvidos a mudança da microbiota intestinal5.

Estudos têm demonstrado que as bactérias da microflora intestinal atuam no balanço Th1/Th2, podendo sua modulação promover o controle de processos infecciosos e imunológicos. Esta modulação pode ser realizada através da administração de probióticos, que são suplementos de microrganismos. O conceito de probióticos data de mais de 100 anos. Entre os séculos XIX e XX, Moro isolou os Lactobacillus em fezes de lactantes alimentados de leite materno, e Tissier, as bifidobacterias, no início do século XX, Metchnikoff relacionou aumento da longevidade em camponeses búlgaros, que consumiam leite fermentado, sendo o consumo deste produto preconizado atualmente pela Organização Mundial de Saúde².

Os probióticos principais são Lactobacillus acidophilus, Lactobacillus casei, Lactobacillus plantarum, Lactobacillus reuteri, Lactobacillus rhamnosus, Lactobacillus paracasei, Bifidobacterium bifidum, Bifidobacterium breve, Bifidobacterium infantis, Bifidobacterium lactis, Bifidobacterium longum,Bifidobacterium adolescentis, Saccharomyces bourlardii, Propionibacterium freudenreichii. São considerados também Escherichia, Enterococcus e Bacillus e o fungo Saccaromyces boulardii. No entanto, apesar de serem benéficos ao organismo e de serem frequentemente adicionados à alimentação infantil, os Lactobacillus bulgaricus e Streptococcus thermophilus não são considerados probióticos $^{2}$.

Para que um probiótico seja satisfatório, as bactérias constituintes devem ser habitantes naturais do trato gastrointestinal, ser resistentes ao suco gástrico e bile, ter identificação taxonômica precisa, colonizar a mucosa intestinal, estar ativas no alimento antes de seu consumo e ser continuamente ingeridos. Sua dose mínima é de 106 UFC6.

Estudos têm avaliado os benefícios do uso de probióticos, melhorando a alergia, decorrente da melhoria do funcionamento da microbiota intestinal nativa ${ }^{6}$. Baseada nestes fatos esta revisão bibliográfica teve por objetivo avaliar a importância do uso de probióticos em rinite alérgica, através da leitura de artigos científicos indexados ao Pubmed no período de 2000 a 2008.

\section{MATERIAL E MÉTODO}

Esta pesquisa refere-se a um estudo de revisão bibliográfica sobre o tema probióticos e rinite alérgica. A fonte de informações utilizada foi o banco de dados Pubmed, no período de 2000 a 2008. Foram incluídos preferencialmente ensaios clínicos, meta-análise e revisões nos idiomas português, Inglês e espanhol, bem como artigos relacionados cujo tema abordado fosse o uso clínico ou experimental de Lactobacillus e Bifidobacterium na rinite alérgica, sendo excluídos estudos com outras formas de alergia. Os descritores utilizados nas respectivas línguas foram "probióticos, rinite alérgica, Lactobacillus, Bifidobacterium".

Quando se pesquisou o descritor Bifidobacterium, 1963 trabalhos foram encontrados, elevando-se para 7012, quando o descritor utilizado foi Lactobacillus. Estes achados sugerem grande interesse nos probióticos, sobretudo nos Lactobacillus, provavelmente devido a sua ampla utilização como suplemento alimentar e, pelo crescente interesse no seu uso, para promoção da saúde. Quando se cruzou os descritores rinite e Lactobacillus, rinite $\mathrm{e}$ Bifidobacterium e rinite e probióticos, estes números decresceram para 26, 10 e 46 artigos respectivamente. 


\section{REVISÃO DA LITERATURA}

A barreira intestinal é nossa maior barreira corporal contra microrganismos e substâncias estranhas. Distúrbios na microbiota intestinal alteram a permeabilidade e diminuem a seletividade intestinal às macromoléculas, fenômeno conhecido como "leaky gut,", ou seja, intestino vazado. Os probióticos podem reforçar as junções intercelulares no trato gastrointestinal, deixando o intestino menos vazado - "less leaky" - bem como aumentar as citocinas que estimulam linfócitos da linhagem Th1, restabelecendo a tolerância oral e diminuindo a resposta alérgica ${ }^{7,8}$. É entendido, então, que a composição da flora intestinal é importante no balanço da resposta imune.

Estudo avaliando crianças de países com alta incidência de doença alérgica, comparando com crianças de países com baixa incidência destas doenças, demonstrou que havia diferença na composição da flora intestinal destas crianças com predomínio de Clostridium e S. aureus nas primeiras e Lactobacillus, Bifidobacterias e Enterococos nas segundas?.

Inúmeros estudos têm observado atividade antialérgica dos Lactobacillus, com poucos estudos envolvendo as Bifidobactérias, sendo esta atividade em ambas as bactérias espécie-específica. Porém, o que se observa nestes estudos é que tanto os probióticos do gênero Lactobacillus quanto do gênero Bifidobacterium têm suprimido a resposta alérgica, promovendo a modulação e regulação do sistema imune ${ }^{10}$.

Aldinucci et al., 2002, investigaram 20 voluntários, 13 com rinopatia alérgica e 7 saudáveis, que participaram do grupo controle, em relação aos efeitos do consumo por quatro meses de iogurte contendo Lactobacillus delbruekii, sub bulgaricus e Streptococcus thermophilus, ou seja dois tipos de probióticos: um Lactobacillus acidophilus e um bifidobacterium ou leite desnatado. Dos 13 indivíduos, 7 receberam $450 \mathrm{~g}$ de iogurte e $6,450 \mathrm{~g}$ de leite parcialmente desnatado, sendo mantida dieta habitual. Foram avaliados antes e depois os seguintes parâmetros: índice de proliferação das células mononucleares e sua liberação de Interferon Gama (INF- $\gamma$ ) e Interleucina-4 (IL-4). Para avaliar rinopatia alérgica utilizou-se testes de funcionalidade nasal (rinometria anterior, rinometria acústica), o Prick teste, teste de provocação nasal específica (TNP), dosagem de IgE específica no sangue, avaliação da sintomatologia e teste do transporte mucociliar nasal. Os pacientes que se alimentaram com iogurte tiveram melhora na sintomatologia e no transporte mucociliar nasal, sendo que os outros parâmetros permaneceram inalterados; já em relação à cultura de células, houve diminuição da secreção de IL-4 e mais secreção de TNF- $\gamma$, sem alteração na taxa de proliferação. Estes achados, segundo os autores, indicam um efeito benéfico no uso deste tipo de alimentação ${ }^{10}$.

As células dendríticas são consideradas as células apresentadoras de antígenos mais eficientes, participan- do de forma importante na iniciação da resposta imune primária e no desenvolvimento da secundária. Estas células podem ser moduladas pelos probióticos e isto seria possível devido a receptores na membrana específicos, denominados "toll-like" para as bactérias. Christensen et al., 2002, demonstraram que diferentes espécies de Lactobacillus exercem diferentes formas de ativação nas células dendríticas ${ }^{11}$.

Kimoto et al., 2004, realizaram estudo com objetivo de avaliar a atividade imunomoduladora de 15 cepas de Lactobacillus. Inicialmente, realizaram In vitro a avaliação da capacidade de indução de citocinas em cultura de macrófagos de murinos linha J774. 1. Neste experimento 6 cepas de Lactobacillus induziram produção de IL2, IL6, TNF- $\alpha$ de forma espécie-específica. Destas cepas, a G50 foi a maior indutora de citocinas, sendo, então, isolada para maiores estudos. Foi também analisado a capacidade de indução de citocinas pela cultura de macrófagos, induzida por cepas L. lactis subsp. Lactis G50 mortas pelo calor, para avaliar se mantinham sua atividade mesmo na forma inviável. Observou-se que esta cepa continuou a induzir produção de citocinas, sugerindo que esta atividade está relacionada com elementos na parede bacteriana. Podese observar, também, que as inviáveis estimularam maior produção de IL12 e menor de IL6, quando comparadas com as cepas viáveis ${ }^{12}$.

Os mesmos autores avaliaram a atividade In Vivo, administrando por via oral Lactobacillus, cepa G50, por 7 dias, a camundongos BALB/c e posteriormente analisando suas células esplênicas, sendo observado que houve aumento da síntese de IL12 e interferon gama e leve diminuição de IL4 e IL6, em relação ao controle. O efeito do Lactobacillus, na produção de anticorpos In vivo, foi também estudado, a partir da imunização dos camundongos com OVM (ovomucoide) medindo-se o nível de anticorpos no plasma. A taxa de IgE específica para o antígeno utilizado (OVM) no soro dos que receberam Lactobacillus G50 apresentou significativa redução $(p<0,01)$ em relação ao controle, bem como de IgG 1, imunoglobulinas envolvidas nos processos alérgicos, não havendo alteração na IgG2a que não está envolvida nestes processos. Quando as células esplênicas dos camundongos sensibilizados com OVM foram incubadas com este antígeno e posteriormente medido a quantidade de OVM-IgE no sobrenadante, podese verificar que nos camundongos que receberam Lactobacillus por via oral houve uma diminuição significativa de IgE específica sem, no entanto, haver alteração nos níveis de interleucinas. Estes achados sugerem que o uso de Lactobacillus, especificamente da cepa L. lactis subsp. Lactis G50, promoveu uma estimulação da linhagem Th1 em detrimento da Th2, fato importante a se considerar, na modulação de condições alérgicas, uma vez que o status imunológico do ser humano está intimamente relacionado ao balanço Th1/Th2. 
Rosenfeldt et al., 2003, observaram que não houve diferença significativa na severidade da dermatite atópica em crianças com dermatite estabelecida, quando utilizaram L. rhamnosus e L. reuteri por 6 semanas em relação ao placebo, porém analisando a criança atópica com prick teste positivo e nível de IgE elevado observou-se diminuição da severidade, bem como dos níveis de proteína eosinofílica catiônica, mas sem alteração dos níveis de IL-2, IL-4, IL-10 e interferon $\gamma$, concluindo que houve um efeito positivo no uso do probiótico ${ }^{13}$.

Peng; Hsu, 2005, realizaram estudo utilizando Lactobacillus paracasi cepa LP33, mortos pelo calor, avaliando seu efeito na melhoraria da qualidade de vida de pacientes com rinite alérgica induzida por poeira doméstica. A partir de um questionário pediátrico de rinoconjuntivite relacionado à qualidade de vida, modificado, observaram que esta forma de utilização foi tão eficaz quanto à administração das formas vivas, na melhora da qualidade de vida ${ }^{14}$.

Xiao et al., 2006, avaliaram o uso de Bifidobacterium longum BB536 por 13 semanas na evolução da polinose decorrente do cedro Japonês e, a partir dos parâmetros avaliados, constataram que o uso deste probiótico não apenas melhorou a sintomatologia, a resposta à medicação e preveniu as formas mais graves, como também promoveu uma diminuição da resposta TH2 em detrimento do aumento da resposta $\mathrm{TH} 1^{15}$.

Takahashi et al., 2006, avaliaram uma sequência de nucleotídeos no DNA do probiótico Bifidobacterium longum, cepa $\mathrm{BB} 536$, que inibiu a produção de $\operatorname{IgE}$ in vitro, além de estimular proliferação de linfócitos B, induzir produção de IL-12 em cultura de macrófagos de murinos linha J774. 1 e aumentar a secreção de Interferon- gama, sem no entanto apresentar efeito sobre IL $4^{16,17}$.

Demonstrando haver um efeito protetor no uso de probióticos na alergia, Morita et al., 2006, utilizaram em 15 indivíduos com níveis séricos elevados de IgE e rinite alérgica leite fermentado preparado com Lactobacillus gasseri TMC0356, na posologia de $200 \mathrm{ml} /$ dia por 4 semanas e observaram declínio significativo $(p<0,05)$ nos níveis séricos de IgE total, bem como de IgE específica para ácaro e pólen do cedro japonês, após 28 dias de exposição comparado ao valor inicial; além destes achados houve aumento do número de células da linhagem TH1 ${ }^{18}$.

Polinose do cedro japonês é uma reação alérgica tipo I mediada por IgE, causada pela exposição à Cryptomeria japonica, cedro-japonês ou araucária do Japão, que atinge $16 \%$ da população Japonesa, sendo, atualmente, considerada um problema de saúde pública, naquele país ${ }^{19}$.

Ogawa et al., 2006, estudaram o desenvolvimento de lesões de pele semelhantes à dermatite atópica em camundongos NC/Nga e sintomas clínicos e parâmetros sanguíneos característicos de rinite alérgica em voluntários saudáveis, durante a época de polinização no Japão pelo
Cryptomeria japonica, durante a administração oral de uma combinação simbiótica de Lactobacillus casei subsp. casei mais dextran, e observaram que houve melhora nas lesões de pele, embora sem alterações significativas com relação à rinite alérgica nestes animais. Ao avaliar os pacientes que utilizaram placebo, observaram que houve uma tendência de aumento dos níveis de IgE específica para este pólen, bem como de citocinas e eosinófilos e diminuição dos níveis de interferon gama em relação aos indivíduos que utilizaram o probiótico, concluindo que, de certa forma, o uso desta associação contribuiu para uma resposta satisfatória na rinite ${ }^{20}$.

Em 2007, Odamaki et al. realizaram um estudo clínico para avaliar os efeitos da suplementação com iogurte enriquecido com Bifidobacterium longum BB536 no tratamento da Polinose do cedro japonês e observaram que, durante o período de polinização, o uso concomitante do probiótico promoveu alívio dos sintomas, ao passo que a elevação dos níveis sanguíneos de eosinófilos e a diminuição do INFy foram suprimidas ${ }^{19}$.

Em novo estudo realizado em 2007, Odamaki et al. observaram que, durante o período de polinização, havia uma modificação na microbiota intestinal dos indivíduos, quando comparada com indivíduos não alérgicos, sobretudo em relação ao Bacteroides fragilis, sendo que o uso do probiótico inibiu esta flutuação, preservando a microbiota adequada. A flutuação na microbiota, neste estudo, foi observada em indivíduos alérgicos no início e no fim da fase polínica, sem haver uma explicação científica concreta, especulando-se que isto poderia ser devido ao estresse provocado pelos sintomas ${ }^{21}$.

Iwabuchi et al., 2007, estudaram 17 cepas de bactérias ácidas lácticas e 15 de bifidobactérias e observaram que em relação à produção de IL12 as primeiras foram mais eficientes. Segundo este estudo, a cepa Bifidobacterium longum BB536 apresentou inibição da produção da IL-4 e IgE antígeno-específica, parcialmente independente das citocinas da linhagem Th1 e independente de citocinas regulatórias com IL-12, IL10 e TNF- $\beta$, que são mediadas pelas células dendríticas apresentadoras de antígenos. Observaram também que a BB536 estimulou maturação das células dendríticas, sobretudo após estimulação antigênica e que promoveu uma inibição da resposta imune TH2 nos linfócitos T de memória ${ }^{22}$.

Sunada et al., 2007, avaliaram os efeitos do Lactobacillus acidophilus cepa L-55 em camundongos BALB/c, com rinite alérgica experimental e observaram que o uso de $10 \mathrm{mg} /$ dia por 4 semanas consecutivas resultou em diminuição da sensibilização nasal, da frequência de espirros a partir da segunda semana de uso, sendo que a medicação controle diminuiu esta sintomatologia apenas na quarta semana. Também houve diminuição da dosagem de IgE específica para OVA (ovalbumina) significativa, no final das 4 semanas, indicando que a administração de 
cepas L-55 de Lactobacillus inibiu a produção de IgE em camundongos sensibilizados ${ }^{23}$.

Kawase et al., 2007, utilizaram Lactobacillus gasseri cepa TMC 0356 e Lactobacillus GG em cobaios sensibilizados pelo pólen da espécie do Cedro-japonês, na dose de 103 UFC por 3 semanas, com objetivo de avaliar presença de obstrução nasal, induzida pela administração de OVA intranasal e alterações nas células imunológicas no lavado nasal e observaram que, em relação à resistência ao fluxo aéreo, após administração nasal de Ovalbumina, houve aumento da resistência em ambos cobaios, porém naqueles que receberam Lactobacillus, esta resistência foi menor que no grupo controle após $10 \mathrm{~min}$ da administração da OVA, sendo estes dados estatisticamente significativos. Em relação as células, houve diminuição no número de leucócitos, sobretudo eosinófilos e neutrófilos, no lavado nasal e diminuição sérica dos níveis de IgE- OVA específica, e apesar destes dados, no estudo, não serem estatisticamente significativos, sugerem uma ação a se considerar destes Lactobacillus, necessitando, então, de maiores estudos, para total confirmação ${ }^{24}$.

Rasche et al., 2007, realizaram coestimulação de células mononucleares periféricas de indivíduos alérgicos ao pólen da gramínea $(n=10)$ e não alérgicos $(n=19)$ com Lactobacillus acidophilus inativo e Escherichia coli cepa Nissle não-patogênica e observaram que ambas bactérias modularam a resposta imune a partir da alteração do CD 23 e expressão de moléculas coestimulatórias. Em relação à produção de citocinas, houve uma resposta dependente da presença ou não de atopia, havendo, porém, um incremento da linhagem Th1 nas células de indivíduos atópicos ${ }^{25}$.

Lisado de Enterococcus faecalis FK-23 (LFK), um produto probiótico de $\mathrm{E}$ faecalis, demonstrou efeito inibitório sobre acúmulo local de eosinófilos induzido por alérgenos e na anafilaxia cutânea ativa em modelos de ratos. Da mesma forma, estudo clínico piloto em humanos demonstrou que o número de eosinófilos no sangue periférico foi significativamente reduzido, após o tratamento em LFK em pacientes com rinite alérgica perene. Portanto, tem sido sugerido que a suplementação de LFK possa desempenhar um papel na prevenção e/ou na transferência da dominância Th2 para um equilíbrio Th1/Th2 ${ }^{26}$.

Devido a estas considerações, Shimata et al., 2007, investigaram os efeitos do uso de antibiótico oral, em camundongos desmamados, e a influência do consumo oral associado ou não de LFK (Lisado de Enterococcus faecalis FK-23) sobre o acúmulo local de eosinófilos alérgenoinduzidos, os níveis de IgE total, IgE antígeno-específica e IgG2a no soro e sobre a microflora intestinal. Para este estudo, utilizaram camundongos tipo Balb/C de 3 semanas, sensibilizados com alérgeno (pólen de Cedro Japonês) modelo experimental e tratados com macrolídeo e macrolídeo + lisado de Enterococcus faecalis FK-23 (LFK) e observaram que as espécimes de Lactobacillus foram eliminadas dis- tintamente nos camundongos expostos à eritromicina no dia 7 e totalmente recuperado, em camundongos tratados com eritromicina-LFK, no dia 28 , mas não recuperado nos camundongos que usaram eritromicina sem LFK. Não foi observada diferença significativa entre os camundongos com ou sem LFK com relação ao acúmulo peritoneal de eosinófilos e IgE específica sérica e IgG2a, porém, na relação IgE total e IgG2a, houve um aumento significativo, nos camundongos que usaram apenas eritromicina, em relação aos que usara LFK ${ }^{26}$.

Giovannini et al., 2007, avaliaram os benefícios do uso prolongado, por 12 meses, de leite fermentado, contendo uma espécie de Lactobacillus casei em 187 crianças de 2 a 5 anos com rinite alérgica e/ou asma, e observaram que houve uma melhora significativa no número de episódios de rinite por ano, porém sem atividade na evolução da asma brônquica ${ }^{27}$.

Kuitunen et al., 2008, administraram uma mistura de probióticos (Lactobacilllus, Bifidobacteria e Propionibacteria) ou placebo em gestantes, no último mês gestacional e em seus bebês, com alto risco de alergia, até os 6 meses de vida, com análise destas crianças aos 5 anos de idade. Os autores não obtiveram diferença significativa na incidência de doenças alérgicas como eczema, rinite, asma e alergia alimentar, no entanto, houve uma menor incidência de doença mediada por IgE, no grupo que recebeu probióticos, nascido de parto cesária ${ }^{28}$.

Dev et al., 2008, avaliaram a ação de Lac-B que é uma mistura das espécies Bifidobacterium infantis e Bifidobacterium longum congeladas a seco, na liberação de histamina em modelo experimental de ratos com rinite alérgica e observaram que o uso destas bactérias ácidas promoveu diminuição da expressão de receptores $\mathrm{H} 1$ na mucosa, bem como da expressão do RNAm da histidina descarboxilase, diminuindo a liberação e ação da histamina e aliviando os sintomas alérgicos. Neste estudo o prétratamento com Lac- B também diminuiu a expressão do RNAm da IL-4 e IL-5 sem, no entanto, ser estatisticamente significativo, quando comparado ao controle. Porém estes dados reforçam a ação destas bactérias na inibição de citocinas responsáveis pela reação alérgica. ${ }^{29}$

Vliagoftis et al., 2008, realizaram estudo de revisão, utilizando o banco de dados Pubmed, sobre o uso de probióticos no tratamento da rinite alérgica e asma e observaram que o uso destes diminuiu as formas graves da rinite alérgica e diminui os dias de medicamentos antialérgicos, sem, no entanto, haver estudos que demonstrassem uma resposta satisfatória, em relação à asma ${ }^{30}$.

Ivory K et al., 2008 observaram, através de estudo duplo-cego placebo controlado, que o uso por cinco meses de Lactobacillus casei Shirota (LcS) promoveu significativa redução nos níveis antígeno-induzidos de IL-5 e IL-6 e interferon gama (IFN- $\gamma$ ) comparado com placebo e aumento de $\operatorname{IgG}$ em detrimento ao decrécimo de $\operatorname{IgE}^{31}$. 


\section{DISCUSSÃO E CONCLUSÃO}

Apesar de existirem estudos significativos, pouco se conhece do uso destas substâncias e dos efeitos de fatores extrínsecos, que alterando a microbiota intestinal, promoveriam enfermidades, dentre elas, a rinite alérgica.

Como a rinite alérgica permanece um desafio constante para os médicos, faz-se necessária a busca de novas alternativas terapêuticas que possam melhorar a qualidade de vida dos pacientes, e o uso de probióticos poderá vir a ser uma alternativa promissora. No entanto, estudos mais abrangentes, com maior número de pacientes, precisam ser realizados, de maneira que os probióticos possam ser utilizados na sua forma plena, permitindo uma melhor abordagem terapêutica com benefícios para os pacientes.

Todos estes estudos demonstram que o uso de próbióticos promove melhoria da resposta imunológica do organismo humano, tendo-se observado ação satisfatória na modulação da resposta alérgica.

A partir dos estudos sobre probióticos e rinite alérgica, pode-se concluir que o uso destas substâncias promoveu resposta satisfatória no controle dos sintomas, na melhora da qualidade de vida e nos marcadores laboratoriais tanto In vitro como In vivo.

\section{REFERÊNCIAS BIBLIOGRÁFICAS}

1. Mello Junior J F De, Mion O. Rinite alérgica. em: Campos Ch De, Olival Ho. Tratado de Otorrinolaringologia. 1 Ed. São Paulo: Roca; 2003.cap.7

2. Morais MB de, Jacob CMA. The role of probiotics and prebiotics in pediatric practice. J Pediatr.2006;82(5):S189-97.

3. Kallinich T, Beier KC, Wahn U, Stock P, Hamelmann E. T-cell costimulatory molecules: their role in allergic immune reactions. Eur Respir J.2007;29(6):1246-55

4. Kaiko GE, Horvat JC, Beagley KW, Hansbro PM. Immunological decision-making: how does the immune system decide to mount a helper T-cell response? Immunology.2008;123(3): 326-38.

5. Kalliomäki M, Salminen S, Arvilommi H, Kero P, Koskinen P, Isolauri E. Probiotics in primary prevention of atopic disease: a randomized placebo controlled trial. Lancet.2001;357:1076-9.

6. Coeuret V, Gueguen M, Vernoux Jp. Numbers and strains of lactobacill in some probiotics products. Int J Food Microbiol.2004;97:147-56.

7. Qin HL, Shen TY, Gao ZG, Fan XB, Hang XM, Jiang YQ, Zhang HZ. Effect of lactobacillus on the gut microflora and barrier function of the rats with abdominal infection.World J Gastroenterol.2005;11:2591-6.

8. Furrie E. Probiotics and allergy. Proc Nutr Soc.2005;64(4):465-9.

9. Monteiro T. Bactérias e aumento da prevalência das doenças atópicas e auto-imunes. Nascer e Crescer. Revista do Hospital de crianças Maria Pia.2005;14(2):92- 5

10. Aldinucci C, Bellussi L, Monciatti G, Passali GC, Salerni L, Passali D, Bocci V. Effects of dietary yoghurt on immunological and clinical parameters of rhinopathic patients. Eur JClin Nutr. 2002;56:1155-61.

11. Christensen HR, Frokiaer H, Pestka JJ. Lactobacilli differentially modulate expression of cytokines and maturation surface markers in murine dendritic cells. J Immunology.2002;168:171-8.

12. Kimoto H, Mizumachi k, Okamoto T, Kurisaki J. New Lactococcus Strain with Immunomodulatory Activity: Enhancement of Th1-Type Immune Response. Microbiol Immunol.2004; 48(2):75-82

13. Rosenfeldt V, Benfeldt E, Dam Nielsen S, Michaelsen K, Jeppesen D, Valerius NH, Paerregaard A. Effect of probiotic lactobacillus strains in children with atopic dermatitis. J Allergy Clin Immunol.2003;111 389-95.
14. Peng GC, Hsu CH. The efficacy and safety of heat-killed Lactobacillus paracasei for treatment of perennial allergic rhinitis induced by housedust mite. Pediatr Allergy Immunol.2005;16(5):433-8.

15. Xiao JZ, Kondo S, Yanagisawa N, Takahashi N, Odamaki T, Iwabuchi N, et al. Probiotics in the treatment of Japanese cedar pollinosis: a doubleblind placebo-controlled trial. Clin Exp Allergy.2006;36(11):1425-35.

16. Takahashi N, Kitazawa H, Iwabuchi N, Xiao J-Z, Miyaji K, IwatsukiK, Saito T. An immunostimulatory DNA sequence from a probiotic strain of Bifidobacterium longum inhibits IgE production in vitro. FEMS Immunol Med Microbiol.2006;46(3):461-9.

17. Takahashi N, Kitazawa H, Iwabuchi N, Xiao J-Z, Miyaji K, IwatsukiK, Saito T. Oral administration of an immunostimulatory DNA sequence from Bifidobacterium longum improves Th1/Th2 balance in a murine model. Biosci Biotechnol Biochem.2006;70(8):2013-7.

18. Morita H, He F, Kawase M, Kubota A, Kurizaki J, Salminen, S. Preliminary human study for possible alteration of serum immunoglobulin E production in perennial allergic rhinitis with fermented milk prepared with Lactobacillus gasseri TMC0356. Microbiol Immunol. 2006;50(9):701-6.

19. Odamaki T, Xiao JZ, Iwabuchi N, Sakamoto M, Takahashi N, Kondo S, et al. Influence of Bifidobacterium longum BB536 intake on faecal microbiota in individuals with Japanese cedar pollinosis during the pollen season. J Med Microbiol. J Med Microbiol.2007;56(10):1301-8.

20. Ogawa T, Hashikawa S, Asai Y, Sakamoto H, Yasuda K, Yutaka M. A new symbiotic, Lactobacillus casei subsp. casei together with dextran, reduces murine and human allergic reaction. FEMS Immunol Med Microbiol.2006;46(3):400-9.

21. Odamaki T, Xiao JZ, Iwabuchi N, Sakamoto M, Takahashi N, Kondo $\mathrm{S}$, et al. Fluctuation of fecal microbiota in individuals with Japanese cedar pollinosis during the pollen season and influence of probiotic intake. J Investig Allergol Clin Immunol.2007;17(2):92-100.

22. Iwabuchi N, Takahashi N, Xiao J-Z, Miyaji K, Iwatsuki, K. In Vitro Th1 Cytokine-Independent Th2 Suppressive Effects of Bifidobacteria. Microbiology and Immunology.2007;51(7):649-60.

23. Sunada Y, Nakamura S, Kamei C. Effects of Lactobacillus acidophilus Strain L-55 on Experimental Allergic Rhinitis in BALB/C Mice. Biol Pharm Bull.2007;30:2163-6.

24. Kawase M, He F, Kubota A, Harata G, Hiramatsu M. Orally Administrated Lactobacillus gasseri TMC0356 and Lactobacillus GG Alleviated Nasal Blockage of Guinea Pig with Allergic Rhinitis. Microbiol Immunol.2007;51(11):1109-14

25. Rasche C, Wolfram C, Wahls M, Worm M. Differential Immunomodulating Effects of Inactivated Probiotic Bacteria on the Allergic Immune Response. Acta Derm Venereol.2007;87:305-11.

26. T Shimada, L Cheng,H-B Shi,A Hayashi,C Motonaga, J Tang,K Enomoto, et al. Effect of Lysed Enterococcus faecalis FK-23 on Allergen-Induced Immune Responses and Intestinal Microflora in Antibiotic-Treated Weaning Mice.J Investig Allergol Clin Immunol.2007;17(2):70-6.

27. Giovannini M, Agostoni C, Riva E, Salvini F, Ruscitto A, Zuccotti G, et al. A randomized prospective double blind controlled trial on effects of long-term consumption of fermented milk containing Lactobacillus casei in pre-school children with allergic asthma and/or rhinitis. Pediatr Res. 2007;62(2):215-20.

28. Kuitunen M, Kukkonen K, Juntunen-Backman K, Korpela R, Poussa T, Tuure T, et al. Probiotics prevent IgE-associated allergy until age 5 years in cesarean-delivered children but not in the total cohort. J Allergy Clin Immunol.2008;123(2):335-41.

29. Dev S, Mizuguchi H, Das AK, Matsushita C, Maeyama K, Umehara H, et al. Suppression of Histamine Signaling by Probiotic Lac-B:a Possible Mechanism of Its Anti-allergic Effect. J Pharmacol Sci.2008;107:159 - 66

30. Vliagoftis H, Kouranos VD, Betsi GI, Falagas ME.Probiotics for the treatment of allergic rhinitis and asthma: systematic review of randomized controlled trials. Ann Allergy Asthma Immunol. 2008;101(6):570-9.

31. Ivory K, Chambers SJ, Pin C, Prieto E, Arqués JL, Nicoletti C. Oral delivery of Lactobacillus casei Shirota modifies allergen-induced immune responses in allergic rhinitis. Clin Exp Allergy.2008; 38(8):1282-9. 